\title{
Aportación de las ciencias forenses al principio de legalidad en la exhumación de fosas comunes en la Comunidad Foral de Navarra
}

\author{
Zientzia Forentseen ekarpena Nafarroako Foru Komunitateko \\ hobi komunen exhumazioen legezkotasun-printzipioari
}

Forensic science contributions to the rule of law in the exhumation of mass graves in the Autonomous Region of Navarre

\author{
Francisco Etxeberria \\ Universidad del País Vasco / Sociedad de Ciencias Aranzadi \\ paco.etxeberria@ehu.eus \\ https://orcid.org/0000-0003-3200-0382
}

Lourdes Herrasti

Sociedad de Ciencias Aranzadi

lourdes.herrasti@gmail.com

\begin{abstract}
Resumen
Se presentan algunas reflexiones sobre los procedimientos metodológicos empleados para realizar las exhumaciones de la Guerra Civil en Navarra y su validez ante procesos administrativos y/o judiciales, de conformidad al plan establecido con carácter oficial por el Gobierno foral. Lo anterior ha permitido un avance significativo en lo que respecta al conocimiento de una verdad formalmente obtenida mediante técnicas y procedimientos específicos, siguiendo los principios generales de la investigación científica en el ámbito de las ciencias forenses. A través de las exhumaciones se ha podido acreditar de forma técnica que muchas personas sufrieron desaparición forzada con resultado de muerte por asesinato, lo que confirma el conocimiento ya establecido por las fuentes históricas y documentales, aportando información más detallada. Al mismo tiempo, los ejemplos de fosas recuperadas han servido para elevar la conciencia respecto de la injusticia de estos hechos e implicar a la ciudadanía en numerosos actos sociales e institucionales, que se han llevado a cabo durante estos años con la puesta en marcha de políticas públicas por parte de la Comunidad Foral de Navarra y de los ayuntamientos.
\end{abstract}

\section{Palabras clave}

Ciencias forenses; exhumación; Navarra; legalidad.

\section{Sumario}

1. INTRODUCCIÓN. 2. NAVARRA: TRES TIPOLOGíAs DE VÍCTIMAS Y UN MISMO MODELO DE INTERVENCIÓN FORENSE. 2.1. Las ej ecuciones extr aj udicial es. 2.2. Muer tes en cautividad. 2.3. Enter r amientos de maquis. 3. EVOLUCIÓN DIACRÓNICA DE LAS EXHUMACIONES EN NAVARRA. 4. CONCLUSIONES: PERFIL DE LAS VÍCTIMAS. 5. RELACIÓN DE TABLAS Y GRÁFICAS. BIBLIOGRAFÍA. 


\begin{abstract}
Laburpena. Zenbait gogoeta aurkezten dira hemen Nafarroan Gerra Zibileko exhumazioak egiteko erabili diren prozedura metodologikoei eta horiek prozesu administratibo eta/edo judizialetan duten balioari buruz, Nafarroako Gobernuak ofizialki ezarritako plana aintzat hartuta. Horri esker, teknika eta prozedura espezifikoen bidez, aurrerapen handia egin da formalki lortutako egiaren ezagutzari dagokionez, zientzia forentseen esparruko ikerketa zientifikoaren printzipio orokorrei jarraikiz. Exhumazioen bidez, modu teknikoan egiaztatu ahal izan da pertsona asko desagerrarazi eta hil egin zituztela. Horrek berretsi egiten du iturri historiko eta dokumentalek jada ezarritako ezagutza, baita informazio zehatzagoa eman ere. Aldi berean, aurkitutako hobien adibideak baliagarriak izan dira bai gertakari horien bidegabekeriarekiko kontzientzia areagotzeko, bai urte hauetan Nafarroako Foru Komunitateak eta udalek politika publikoak abian jarrita gauzatu dituzten ekitaldi sozial eta instituzional askotan herritarrak inplikatzeko.
\end{abstract}

Gako hitzak. Auzitegiko zientziak; exhumazioa; Nafarroa; legezkotasuna.

\begin{abstract}
Some observations are presented here on methods used to carry out the exhumations of the Spanish Civil War in Navarre and their validity in administrative and/or judicial proceedings, in accordance with the plan officially established by the Regional Government. As a result, significant progress has been made in obtaining the truth by means of techniques and procedures used in the field of Forensic Sciences. The exhumations have provided evidence that many people suffered forced disappearance resulting in death by murder. Thus, confirming the knowledge already established by historical and documentary sources, and providing more detailed information. Furthermore, the examples of graves recovered have served to raise awareness of the injustice of these events and involve the public in numerous social and institutional ceremonies. These have been carried out over the years with the implementation of public policies by the Autonomous Community of Navarre and the local municipalities.
\end{abstract}

Keywords. Forensic sciences; exhumation; Navarre; rule of law.

\section{Introducción}

Son varios los trabajos de revisión y síntesis que se han publicado sobre las exhumaciones llevadas a cabo en las dos últimas décadas que han sido realizadas de conformidad a protocolos homologados por equipos cualificados en el ámbito forense ${ }^{1}$. Cualquier reflexión sobre las exhumaciones realizadas no puede olvidar el esfuerzo que hicieron muchos de los familiares de las víctimas sin contar con ayuda profesional ni institucional en lo que en Navarra se han llamado las «exhumaciones tempranas» en el final de la dictadura franquista. En la actualidad el derecho que asiste a estas familias parece reconocido por las instituciones y la sociedad y, probablemente, sea este el mayor éxito del movimiento memorialista.

Tampoco se puede olvidar el reciente trabajo monográfico Bajo tierra. Exhumaciones en Navarra 1939-2019, que recoge de forma exhaustiva las investigaciones realizadas y los resultados alcanzados en el marco de un plan oficial de investigación impulsado por el Gobierno de Navarra² .

1 Etxeberria (coord.), 2020; Etxeberria y Solé, 2019.

2 Gastón y Layana, 2019. 
Con todo, no han faltado críticas a la ausencia de implicación judicial, aunque solo sirviera para acreditar una verdad que faltaba en este ámbito. En lo que se refiere a la persecución de los crímenes de la represión franquista con resultado de muerte, las diferentes tipologías han sido determinadas muy recientemente por especialistas en derecho del siguiente modo:

- Ejecuciones extrajudiciales.

- Ejecuciones sumarias.

- Fallecidos en acción de guerra, combatientes y no combatientes ${ }^{3}$.

- Muertos en cautividad.

Esta clasificación es imprescindible para establecer una verdadera interpretación de los casos ante un supuesto proceso judicial como se ha reclamado desde varios sectores. Sin duda, todas ellas son muertes que hay que atribuir a quienes provocaron la guerra tras la sublevación de una parte sustancial del Ejército y además ejercieron la represión definida como «franquista» desde el punto de vista historiográfico. Pero probablemente no todas las «víctimas del franquismo con resultado de muerte» tienen el mismo recorrido en un posible procedimiento seguido ante los tribunales de justicia, sean estos internos o internacionales ${ }^{4}$.

Por su parte, también el Fondo Documental de la Memoria Histórica de la Universidad Pública de Navarra ha realizado una investigación formal y oficial con un esfuerzo notable para establecer una clasificación de las distintas categorías y subcategorías de las víctimas con sus correspondientes definiciones. Pero sigue siendo necesario buscar un consenso en el terreno de los especialistas en historia contemporánea para poder establecer siquiera un censo de víctimas con criterios aceptados y equivalentes que se valide y se haga oficial por las instituciones ante lo inespecífico del concepto de «victimas franquistas $»^{5}$ (tabla 1). Efectivamente, no es lo mismo morir en acción de guerra, en cautividad, o convertirse en un desaparecido tras ser detenido por los responsables que ejercían el control y la autoridad tras la sublevación de julio de 1936.

Tabla 1. Cifras del número de víctimas de la represión franquista en Navarra aportadas en los últimos años

\begin{tabular}{ccccc}
$\begin{array}{c}\text { Censos de víctimas franquistas } \\
\text { con resultado de muerte }\end{array}$ & $\begin{array}{c}\text { Garzón, } \\
2008\end{array}$ & $\begin{array}{c}\text { Espinosa y } \\
\text { Ledesma, 2012 }\end{array}$ & $\begin{array}{c}\text { Babiano et } \\
\text { al., 2018 }\end{array}$ & $\begin{array}{c}\text { Investigación oficial } \\
\text { UPNA, 2021 }\end{array}$ \\
\hline Navarra & 3431 & 3280 & 4182 & $\begin{array}{c}\text { 2994 asesinadas + } \\
426 \text { en cautividad }\end{array}$ \\
\hline
\end{tabular}

3 Esta categoría no se aplica en Navarra si bien puede valer para aquellas personas que, siendo originarias de Navarra, participaron y murieron en la guerra en otras regiones.

4 Gogora, 2019.

5 Majuelo et al., 2019. 
En relación al número de personas fallecidas durante la guerra y la dictadura, y a los efectos de establecer una tipología de víctimas, en el «Anteproyecto de Ley de Memoria Democrática» actualmente en trámite se considera víctima a toda persona, con independencia de su nacionalidad, que haya sufrido, individual o colectivamente, daño físico, moral o psicológico, daños patrimoniales, o menoscabo sustancial de sus derechos fundamentales, como consecuencia de acciones u omisiones que constituyan violación de los derechos humanos durante el periodo que abarca el golpe de estado del 18 de julio de 1936, la posterior guerra y la dictadura, incluyendo el transcurrido hasta la entrada en vigor de la Constitución española de 1978, y en particular a las personas fallecidas o desaparecidas como consecuencia de la guerra y la dictadura ${ }^{6}$.

Pero si nos centramos en la obligación de hacer un censo de víctimas, como se contempla en dicho Anteproyecto de Ley (Artículo 9. Censo nacional de víctimas), se debería establecer sin más retrasos una subclasificación consensuada en lo que respecta a víctimas con resultado de muerte según las tipologías de victimación, utilizando los criterios que ya se han recomendado desde el ámbito de los Derechos Humanos, como pueden ser los recogidos en la siguente tabla:

Tabla 2. Propuesta de tipología de las víctimas formulada por Gogora (2019)

\begin{tabular}{|l|l|l}
\hline Tipologías de victimación con resultado de muerte & $\begin{array}{c}\text { Causadas por } \\
\text { republicanos }\end{array}$ & $\begin{array}{c}\text { Causadas por } \\
\text { sublevados }\end{array}$ \\
\hline Fallecidos en acción de guerra & combatientes & no combatientes \\
\hline Ejecuciones extrajudiciales & \\
\hline Ejecuciones sumarias & \\
Muertos en cautividad/custodia & \\
Otras causas
\end{tabular}

Como hemos dicho, para ello ya se ha avanzado mucho en el caso de Navarra a través de la Universidad Pública de $\mathrm{Navarra}^{7}$, que cuenta con el decidido impulso del Gobierno de Navarra y de su Parlamento.

En este territorio las exhumaciones llevadas a cabo desde el año 2005, en que se realizó la primera por encargó oficial del Ayuntamiento de Fustiñana siǵuien-

${ }^{6}$ Asimismo, en este Anteproyecto de Ley se contemplan otros tipos de víctimas represaliadas relativas a exilio, incautación de bienes, etc.

7 Majuelo et al., 2019. 
do una metodología científica ${ }^{8}$, han estado condicionadas por la Ley de Memoria Histórica del año 2007 y por el Auto del 28 de marzo de 2012 de la Sala de lo Penal del Tribunal Supremo, cuyo razonamiento jurídico cuarto dice lo siguiente:

Excluida ya, en general, la posibilidad del enjuiciamiento penal de los autores de los actos de que se trata, es claro que esa clase de legítimas pretensiones no podrá canalizarse hacia el proceso penal ni llegar a concretarse en declaraciones de responsabilidad exdelicto a cargo de aquellos. No obstante, esto no deberá ser obstáculo para que, en presencia de indicios objetivables de la existencia de restos de posibles víctimas de delitos susceptibles de localización —salvo cuando de la propia noticia contenida en la denuncia o querella se derive la inexistencia de responsabilidad penal actualmente exigible- pueda instarse del Juez de Instrucción competente según el art. 14.2 Lecrim, la práctica de las diligencias diriǵidas a datar aquellas acciones criminales y, si fuera necesario, a la identificación de los afectados, para proceder luego, consecuentemente, en derecho. Pues si hay algo inobjetable desde cualquier punto de vista — por imperativo del respeto debido a la dignidad de todas las personas ( $\operatorname{art} .10 .1^{\circ} \mathrm{CE}$ ), y hasta por razones de policía sanitaria mortuoria (D. 2263/1974, de 20 de julio) — es que los restos de quienes hubieran sufrido muertes violentas no pueden permanecer en el anonimato ni fuera de los lugares propios de enterramiento. $\mathrm{Y}$ tampoco cabe imponer a sus familiares el gravamen representado por tal clase de situaciones, moral y jurídicamente insostenibles.

A esta sentencia del año 2012 se vuelve a sumar otra, la núm. 138/2021 de la Sala de lo Penal del Tribunal Supremo de fecha 17 de febrero de 2021, relativa a la investigación de la fosa de los maestros exhumada por la Sociedad de Ciencias Aranzadi a partir del impulso de la asociación soriana Recuerdo y Dignidad. El Tribunal Supremo, reiterando los arǵumentos del año 2012, señala, entre otras cuestiones, que:

no es posible en nuestro sistema procesal una actividad jurisdiccional de mera indagación sin una finalidad de imposición de una pena. Ello implica la existencia de responsabilidades penales exigibles y con, al menos potencialmente, la presencia del imputado con pleno ejercicio de su derecho de defensa y con la intervención activa que la ley procesal establece y le garantiza (art. 118 y ss. de la ley procesal penal).

Y prosigue,

la búsqueda de la verdad es una pretensión tan legítima como necesaria. Corresponde al Estado a través de otros organismos y debe contar con el concurso de todas las disciplinas y profesiones, especialmente de los historiadores. Pero

8 Etxeberria y Herrasti, 2017. 
no corresponde al juez de instrucción, cuya función aparece definida en la ley procesal con un objeto de indagación que se va concretando en el devenir procesal y ve limitado su ejercicio por las normas que rigen el proceso penal y el derecho penal sustantivo. Es preciso un hecho con apariencia de delito y un posible imputado vivo.

Por otra parte, se debe considerar la amplia regulación normativa establecida por las comunidades autónomas en materia de fosas comunes y exhumaciones tal y como han puesto de manifiesto Cuesta y Odriozola ${ }^{9}$, que en Navarra tiene el siguiente desarrollo:

La Ley Foral 33/2013, de 26 de noviembre, de reconocimiento y reparación moral de las ciudadanas y ciudadanos navarros asesinados y víctimas de la represión a raíz del golpe militar de $1936^{10}$. En su artículo 4 se establecen las siguientes Medidas:

1. Las medidas que la Administración de la Comunidad deberá llevar a cabo para el cumplimiento de los objetivos señalados en el artículo 1 serán las siguientes:

a) Aplicar el Protocolo de Exhumaciones de la Comunidad Foral de Navarra, aprobado por Orden Foral 772/2011, de 7 de noviembre, del Consejero de Presidencia, Administraciones Públicas e Interior, así como las actualizaciones o mejoras que pudieran ser necesarias.

b) Mantener y actualizar el mapa de fosas de Navarra.

c) Actuar de forma directa en la recuperación de los restos de las personas desaparecidas.

d) Salvaguardar, señalizar y proteger los lugares de enterramiento.

e) Retirar las menciones o símbolos franquistas que pudieran existir.

f) Desarrollar convenios y otros instrumentos para el estudio y el conocimiento de los hechos acaecidos en Navarra durante la Dictadura franquista.

g) Proteger los monumentos de recuerdo existentes para las víctimas del franquismo e impulsar declaraciones y menciones de reconocimiento para estas personas.

h) Apoyar a las víctimas de los robos de bebés causados por la represión de la dictadura franquista, tanto a sus familias como a las personas que buscan su identidad biológica.

9 Cuesta y Odriozola, 2018.

${ }^{10}$ http://www.lexnavarra.navarra.es/detalle.asp?r=32889. En opinión de Garmendia y García Funes (2015) «la ley tiene un considerable peso reparador con un marcado carácter 'corpocéntrico', dada la dimensión que cobran las exhumaciones y las 'lógicas tecno-científicas arqueológicas y forenses'». 
2. Las actuaciones definidas en el apartado anterior se realizarán en colaboración con los ayuntamientos, las asociaciones de familiares de fusilados, las asociaciones de Memoria Histórica y las entidades académicas.

3. Se establecerán en los Presupuestos Generales de Navarra las partidas económicas necesarias para atender el cumplimiento de los objetivos de esta Ley Foral, en su caso a través de las correspondientes subvenciones a entidades públicas y privadas.

Y también la Orden Foral 772/2011, de 7 de noviembre, del Consejero de Presidencia, Administraciones Públicas e Interior, por la que se aprueba definitivamente el Protocolo de exhumaciones de la Comunidad Foral de Navarra a la que se alude en el artículo 7 de la Ley Foral de 2013.

Nada difiere de lo recomendado un año más tarde en el Informe del relator especial de la ONU Pablo de Greiff ${ }^{11}$ y del Protocolo de Minnesota sobre la investigación de muertes potencialmente ilícitas 2016 (Versión revisada del Manual de las Naciones Unidas sobre la Prevención e Investigación eficaces de las ejecuciones extralegales, arbitrarias o sumarias de 1991) ${ }^{12}$, ni del protocolo de exhumaciones establecido en la Orden PRE/2568/2011, de 26 de septiembre. Protocolos que se basan en principios generales que deben regir estas investigaciones forenses como son la efectividad, la exhaustividad, la independencia, la imparcialidad y la transparencia.

Tampoco puede olvidarse que, en materia de exhumaciones, en Navarra es preceptivo el permiso correspondiente del servicio de Patrimonio, que se regula por la Ley Foral 15/2005, de 22 de noviembre, del Patrimonio Cultural Navarro referente al Patrimonio Arqueológico, así como el Decreto Foral 218/1986, de 3 de octubre, por el que se establece la concesión de licencias para la realización de excavaciones y prospecciones arqueológicas.

Así las cosas, cabe preguntarse, ¿se han hecho las cosas bien en el plano técnico? ¿Las actuaciones llevadas a cabo en la Comunidad Foral de Navarra pueden tener alguna validez administrativa o aplicación en la jurisdicción penal, civil o contencioso administrativa, llegado el caso?

Frente a quienes han opinado que no, sin haber ejercido ni un solo trámite ante estas instancias, ni tener formación en el ámbito del derecho, nosotros consideramos que estamos en condiciones de demostrar lo contrario, esto es, que las exhumaciones en todos los lugares donde se han llevado a cabo, y en particular en Navarra, se han realizado y se realizan en un marco normativo regulado oficialmente

\footnotetext{
11 Relator especial sobre la promoción de la verdad, la justicia, la reparación y las garantías de no repetición y su informe sobre España 2014. https://documents-dds-ny.un.orǵ/doc/UNDOC/GEN/ G14/090/55/PDF/G1409055.pdf?OpenElement.

${ }^{12} \mathrm{Y}$ actualizado en 2016 https://www.ohchr.org/Documents/Publications/MinnesotaProtocol_SP.pdf.
} 
de forma específica y cumpliendo criterios homologados a nivel internacional. De hecho, así puede llegar a concretarse si se constituye una Fiscalía de Sala de Memoria Democrática y Derechos Humanos ${ }^{13}$ que intervendrá en su caso en la defensa de la legalidad y los derechos humanos como se pretende en el Anteproyecto de Ley de Memoria Democrática que podría suponer, para empezar, una validación o reconocimiento de carácter judicial a todo lo efectuado hasta el presente.

A esta nueva fiscalía de sala, que se cree para la investigación de los hechos que constituyan violaciones del derecho internacional de Derechos Humanos y del derecho internacional humanitario, se le atribuyen asimismo funciones de impulso de los procesos de búsqueda de las víctimas de los hechos investigados para lograr su debida identificación y localización. Para ello, practicará las diligencias previstas legalmente, recibirá denuncias y ejercitará la acción pública en cualquier tipo de procedimiento, exiǵiendo las responsabilidades que procedan, cuando se refieran a hechos que constituyan violaciones de derecho internacional de Derechos Humanos y del derecho internacional humanitario, siempre que pudieran ser constitutivos de delito. Asimismo, facilitará y coordinará los instrumentos de cooperación internacional para la reparación de las víctimas.

Otra cosa distinta es el recorrido que puedan tener estos procedimientos judiciales, propiamente dichos, ante la apreciación práctica de los operadores de justicia dentro de sus competencias. A este respecto, ya se han escrito varias monografías muy esclarecedoras ${ }^{14}$, y no parece que las posibilidades de enjuiciar los hechos con todas sus consecuencias sean tan sencillas.

Pero lo que no se puede es atribuir estas dificultades o limitaciones precisamente a los profesionales que han desarrollado su trabajo de forma correcta. Sorprenden entonces las críticas que se han realizado hacia los trabajos forenses, sean estos arqueológicos, antropológicos o genéticos, y olvidan que, todo lo que se ha realizado en materia de memoria histórica tiene validez documental, testifical y pericial,

nace de la tierra, de las fosas comunes, de todas y cada una de las excavaciones realizadas en estos últimos años, de los actos de recuerdo y homenaje que han tenido lugar en cada pequeño rincón del país, de las entrevistas, programas y documentales elaborados con ese objetivo de grabar lo olvidado y, también, de las líneas escritas en ese esfuerzo por sacar a la luz todo lo ocurrido y lo sufrido ${ }^{15}$.

${ }^{13}$ La idea de crear una fiscalía especial ya fue expuesta por el profesor Carlos Villar Durán en 2005 en un artículo ampliamente difundido titulado «Las obligaciones del Estado español en materia de desapariciones forzadas» de notable influencia en el movimiento memorialista.

14 Capellà, 2006; Martín Pallín y Escudero Alday, 2008; Escudero Alday y Pérez González, 2013; Galella, 2014.

${ }^{15}$ Martín Pallín y Escudero Alday, 2008. 
De forma gráfica también lo expresa Sáez al referirse al impacto que le produjeron las fotografías publicadas en El País el 30 de marzo de 2013 sobre la exhumación que realizamos en la fosa de Loma de Montija (Burgos):

Es el poder de la imagen, testimonios inquebrantables de la barbarie del pasado inmediato. Imágenes que han socavado consensos políticos básicos, que han removido la memoria colectiva, que han propiciado la deslegitimación de la transición y cuestionado el relato oficial. La indiferencia de jueces y autoridades administrativas supone un factor añadido de deslegitimación institucional ante un sector de la sociedad, porque expresa y actualiza la injusticia de la dictadura ${ }^{16}$.

Así, en el llamado el «giro forense» que ha experimentado la memoria histórica, los informes forenses realizados han transformado, en el sentido propio de las ciencias forenses, los «indicios» en «evidencias» que, gestionadas de forma adecuada, pueden llegar a ser validadas por las autoridades judiciales para convertirse en «pruebas» y tener sus efectos. Lo que, como siempre ocurre en cualquier procedimiento judicial, dependerá de la apreciación de los propios jueces y/o tribunales encargados de evaluarlas y de la genialidad de todos los operadores judiciales que las impulsan. De la misma manera que han sido validados los resultados de los análisis realizados por el Instituto Nacional de Toxicología y Ciencias Forenses, perteneciente al Ministerio de Justicia, en nueve fosas con un total de 40 esqueletos recuperados hasta el año 2012, aun cuando todas las exhumaciones se hicieron sin presencia judicial ${ }^{17}$.

Lo cierto es que son escasos los procedimientos judiciales puestos en marcha, si tenemos en cuenta que hasta el momento se han exhumado en España 830 fosas comunes y recuperado los restos de más de 10400 víctimas ${ }^{18}$, a pesar de que en muchas de las intervenciones se había reclamado la «tutela judicial».

De hecho, el inicio de diligencias previas en alǵunos juzǵados de instrucción en donde ha sido posible, ha acabado siempre en autos de archivo bajo el argumento de la prescripción y, salvo excepciones notables ${ }^{19}$, en la mayor parte de los

\footnotetext{
16 Sáez, 2013.

17 Alonso et al., 2012.

18 Herrasti, 2020.

19 Así algunas experiencias como la de la fosa de Piedrahita de Babia (León), por la que se siguieron Diliǵencias Previas 487/2002 en el Juzǵado de Instrucción $n^{\circ} 1$ de Villablino y en la que el día 13 de septiembre de 2002, acompañados por dos funcionarios del Juzgado de Instrucción, revisamos los restos esqueléticos depositados en cajas individualizadas en el Depósito de Cadáveres de esa misma localidad. O la más reciente en la fosa de La Riba de Escalote en Soria (2019), en donde ha existido una tutela judicial de toda la investigación y los informes generados han servido, tras su presentación formal y ratificación, para dar cuerpo a una instrucción judicial que sigue su curso en la Audiencia Provincial de Soria.
} 
casos sin ejercer ninguna investigación. Como han señalado Jiménez y Doñate ${ }^{20}$, lo primero es investigar los hechos y generar con ello una verdad que faltaba, para dejar a una segunda fase la posibilidad de aplicar la prescripción si fuera necesaria.

La obligación de instruir la causa ya fue planteada por las juezas Inés Soria y Amaya Olivas, en 2006, con un clarificador escrito titulado «Una oportunidad perdida», que entre otras cosas dice:

Las diligencias encaminadas a la localización de las fosas y lugar de enterramiento, a la exhumación y a la recuperación de los restos, permiten por un lado la adecuada protección de los perjudicados, protección que no es completa si no se pone a su disposición todos los recursos efectivos para la localización e identificación de los fallecidos por muerte violenta, consiguiendo no sólo la recuperación de los restos de sus familiares para poder darles adecuada sepultura sino para que puedan recuperar su memoria y su dignidad, pudiendo obtener su justa reparación, permitiéndoles cerrar de verdad las heridas abiertas y nunca recompensadas y su duelo personal.

Y continúan:

Una vez que se disponga de la documentación suficiente sobre la localización de los restos se procederá a acordar la exhumación de los cadáveres y su posterior identificación. En relación con la exhumación, las particularidades del caso requieren la intervención de técnicos cualificados que han de llevar a cabo las tareas de dirección y organización. Dichas tareas pueden durar varios días, siendo precisa una gran organización para que una vez dividido el trabajo entre los distintos profesionales, su labor sea lo más efectiva posible sin merma de las garantías necesarias para la posterior identificación de los restos y la recogida de vestigios e información de lo realmente sucedido, alterando en la menor medida posible el escenario donde ocurrieron los hechos. Los grupos previamente formados, compuestos por técnicos cualificados actuarían de forma similar a los peritos judiciales, siendo llamados por los juzgados para su intervención en cada caso. Para la adecuada consecución de sus fines sería aconsejable que hubiera un equipo formado por antropólogos forenses, patólogo forense, odontólogo forense y biólogo forense. El papel del antropólogo y del arqueólogo son claves en este proceso de exhumación. El arqueólogo excava y levanta los restos, y luego ya es un material propio del antropólogo físico, para llegar a su identificación. La dirección y la organización debe dejarse a manos de los expertos, quedando el juez en la función de garante, velando por acordar las diligencias necesarias para dotar a la exhumación de las garantías de los levantamientos

${ }^{20}$ Jiménez y Doñate, 2012. 
judiciales, autorizando las diligencias necesarias para que pueda llevarse a cabo la exhumación, interviniendo en casos de que no hubiera consentimiento de los particulares, autorizando en caso de ser necesario las pruebas de ADN para la identificación de los restos. Garantizando con sus decisiones el máximo respeto y protección de los derechos afectados ${ }^{21}$.

Un ejemplo concreto y digno de consideración es el auto que dictara Virǵinia Domínguez de la Fuente, jueza del Juzgado de Instrucción núm. 1 de Salas de los Infantes (Burgos), en fecha 1 de septiembre de 2009, relativo a la fosa de Rabanera del Pinar, en donde localizamos cinco esqueletos completos con signos de muerte violenta analizados en un informe forense exhaustivo, y en el que se dice textualmente:

Primero.- «En primer lugar se ha de poner de manifiesto que se trata de crímenes acaecidos hace más de setenta años y que en todo caso han prescrito. No obstante, más allá de ser considerados simples asesinatos, estos fueron detenciones ilegales y secuestros de los cuales nunca se dio facilidades para encontrar a las víctimas con lo que nos encontramos en una situación que se ha perpetuado en el tiempo y que es necesario ponerla fin, para de esta forma acabar con esta actividad delictiva indefinida. Ni que decir tiene que para este juzgado toda víctima que padeció delitos violentos, merece total respeto con independencia de la ideología con lo que no se debe hacer diferenciación entre ellas por tales circunstancias.

Segundo.- En segundo lugar, más allá de valorar que clase de conducta delictiva acaeció y si ha prescrito o no, lo esencial es tratar de reparar el daño que se ocasionó a las víctimas o por lo menos intentar mitigarlo. En una sociedad con un derecho penal en cambio, en el que se está abogando por dar mayor protagonismo a la víctima de los delitos y sus familiares, se debe intentar favorecer que cualquier víctima pueda cicatrizar sus heridas y superar la victimación secundaria que se produce cuando se sufre un delito. Por lo tanto y para no conculcar el principio de igualdad que rige nuestro ordenamiento, estas personas con independencia del tiempo transcurrido deben tener la oportunidad de ser reparadas o compensadas, si así lo desean, por los hechos delictivos sufridos en la persona de sus familiares y amigos.

Tercero.- [...] En el caso que nos ocupa lo que es innegable es que si en su día no tuvieron la oportunidad de ser compensados por el daño sufrido, se les debe dar la oportunidad de poder hacerlos ahora, aun cuando hayan transcurrido tantos años, pues si la responsabilidad penal de los autores ha prescrito, no pudieron aplicarse normas actuales con retroactividad por ser sancionadoras

${ }^{21}$ Pertenecientes a la asociación «Jueces para la Democracia» (http://www.juecesdemocracia.es/ actividades/jornadas/2006/pueblo/Exhumacion.Amaya\%20e\%20Ines.pdf). 
o restrictivas de derechos, a la inversa nuestro Derecho permite la retroactividad de disposiciones que puedan ser favorables, que como en este supuesto podrían ser todas las que contemplan la restitución, reparación y compensación del daño a las víctimas de delitos, o en su caso a sus familiares, que así lo deseen o lo necesiten para superar los trágicos acontecimientos que acaecieron en España en aquellos años, con independencia de la ideología que tuvieran, pues se ha de reiterar que no se debe hacer distinciones al respecto».

Tras los correspondientes informes forenses validados por la autoridad, este auto judicial da las claves de los derechos que asisten a los familiares y la manera de actuar en lo que se refiere a la exhumación de fosas. Representa una digna consideración por parte de esta jueza hacia las víctimas que nunca antes tuvieron una investigación oficial, si bien, para muchos, la mera instrucción de la causa es insuficiente si luego no se produce la posibilidad de enjuiciar los hechos, cuestión que no depende de los análisis forenses sino de otros condicionantes jurídicos en donde las discrepancias entre los especialistas son llamativas.

Esta realidad nos obliga a considerar la pertinencia de las «Observaciones finales del Comité contra la Desaparición Forzada sobre el informe presentado por España en virtud del artículo 29, párrafo 1, de la Convención del 12 de diciembre de 2013 » relativas a la responsabilidad penal y cooperación judicial en materia de desaparición forzada (artículos 8 a 15). Así, en el punto 9,

el Comité toma nota con satisfacción de que, según el derecho penal vigente, los delitos de lesa humanidad son imprescriptibles. Asimismo, acoge con beneplácito la información brindada por el Estado parte según la cual, de conformidad con el artículo 132 del Código Penal, los plazos de prescripción en relación con los delitos permanentes, equivalentes en el derecho interno a los delitos de carácter continuo en la Convención, comenzarían a computarse a partir de que «se pone término a la actuación dolosa enjuiciada». Sin embargo, observa con preocupación la información recibida acerca del criterio adoptado por el Tribunal Supremo en relación con la investigación de presuntos casos de desaparición forzada (sentencia 101/2012) en virtud del cual, entre otros fundamentos tales como la existencia de una ley de amnistía y la muerte de los presuntos responsables, sostuvo que «[...] la argumentación sobre la permanencia del delito no deja de ser una ficción contraria a la lógica jurídica. No es razonable argumentar que un detenido ilegalmente en 1936, cuyos restos no han sido hallados en el 2006, pueda racionalmente pensarse que siguió detenido más allá del plazo de prescripción de 20 años, por señalar el plazo máximo [...]» (arts. 8, 12 y 24).

Pero todo lo anterior se desenvuelve en un plano doctrinal que, aunque resulte necesario, no logra superar los planteamientos teóricos iniciales y contrasta con la realidad práctica de la reclamada judicialización con todas sus consecuencias. 
Tras veinte años de investigaciones forenses en los que se van recuperando desaparecidos y, a su vez, van desapareciendo los protagonistas de aquellos hechos, consideramos que, si hemos de estar esperando hasta que se despeje esta fronda judicial, muy posiblemente para entonces ya no quede ni siquiera el interés por investigarlos. Cierto es que estas dilaciones forman parte del modelo de impunidad que no han establecido los técnicos forenses precisamente. Al mismo tiempo se pierde el rastro de las fosas o estas han desaparecido para siempre, como ya ocurre en Navarra, en donde el $53 \%$ de las prospecciones o búsquedas han dado resultado negativo (tablas 3 y 4 ).

Tabla 3. Proporción de fosas prospectadas que no se han encontrado por CCAA

\begin{tabular}{|lc|}
\hline \multicolumn{1}{|c}{ Comunidad autónoma } & $\%$ \\
\hline Andalucía & $13 \%$ \\
\hline Castilla y León & $18 \%$ \\
\hline Comunitat Valenciana & $20 \%$ \\
\hline Galicia & $35 \%$ \\
\hline Illes Balears & $47 \%$ \\
\hline Navarra & $53 \%$ \\
\hline Euskadi & $63 \%$ \\
\hline
\end{tabular}

Tabla 4. Porcentaje de fosas que no se han encontrado del total de las intervenidas en las distintas CCAA

\begin{tabular}{|lccccc|}
\hline $\begin{array}{c}\text { Información } \\
2020\end{array}$ & $\begin{array}{c}\text { Fosas buscadas } \\
\text { y prospectadas }\end{array}$ & $\begin{array}{c}\text { Fosas no } \\
\text { encontradas }\end{array}$ & $\begin{array}{c}\text { Fosas } \\
\text { exhumadas }\end{array}$ & $\begin{array}{c}\text { Restos } \\
\text { recuperados }\end{array}$ & Referencia \\
\hline Euskadi & 127 & $81(63 \%)$ & $46(36 \%)$ & 110 & Herrasti \\
\hline Navarra & 126 & $67(53 \%)$ & $59(46 \%)$ & 241 & Herrasti \\
\hline Castilla y León & 217 & $54(24 \%)$ & $163(75 \%)$ & 1909 & Montero \\
\hline Illes Balears & 21 & $10(47 \%)$ & $11(52 \%)$ & 110 & Govern \\
\hline Galicia & 42 & $15(35 \%)$ & $28(64 \%)$ & 75 & ARMH \\
\hline Extremadura & 90 & $47(52 \%)$ & $43(47 \%)$ & 438 & Chávez \\
\hline Andalucía & 148 & $20(13 \%)$ & $128(86 \%)$ & 4700 & Guijo \\
\hline
\end{tabular}


La realidad es que las exhumaciones se encuentran condicionadas por la Ley de Memoria Histórica de 2007 y, de forma más concreta, por el Auto del 28 de marzo de 2012 de la Sala de lo Penal de Tribunal Supremo, razonamiento jurídico cuarto (ya citado en la páǵinas anteriores de este mismo texto).

Por otra parte, la simple descalificación de la metodología y los procedimientos seguidos en las exhumaciones que algunos han pretendido implican una crítica al Gobierno de la Comunidad Foral, al Parlamento de Navarra, a la Dirección General de Paz, Convivencia y Derechos Humanos del Departamento de Relaciones Ciudadanas y de forma más concreta al Instituto Navarro de la Memoria encarǵado del desarrollo del proyecto de «Exhumaciones y banco de $\mathrm{ADN} »^{22}$, junto a otros tan pertinentes como son el «Centro de Documentación», «Luǵares de memoria», «Escuelas con memoria», «Homenajes», «Retirada de simbología franquista»... ¿Acaso cabe criticar a los historiadores que han podido localizar documentos probatorios de crímenes y no han acudido a la administración de justicia para denunciar los hechos a fin de iniciar los correspondientes procesos? ¿Conocen estos profesionales que, con la vigente Ley de Enjuiciamiento Criminal, cualquiera que como consecuencia de su actividad profesional conociera un hecho delictivo perseguible de oficio, tiene obligación de denuncia? ¿Debería en estos supuestos habilitarse un procedimiento específico en justa defensa de los derechos de las víctimas?

Especialmente constante en las críticas al modelo seguido ha sido el Equipo Nizkor que ha expuesto sus opiniones en diversos trabajos. También la Federación de Foros por la Memoria al señalar que

las administraciones autonómicas se atribuyen competencias en materia de localización, exhumación e identificación de personas desaparecidas. Por muy loable que sea desde un punto de vista ético, moral, incluso político para con las víctimas del franquismo, no podemos olvidar que estamos hablando de crímenes, en concreto de los más graves crímenes que un estado puede cometer en cualquier sociedad o país, es decir, de crímenes de guerra, contra la paz y de lesa humanidad, y por lo tanto, según la ley procesal española (Lecrim), su investigación y persecución corresponden a los juzgados de instrucción y tribunales penales españoles. Recordamos que la exhumación e identificación de las fosas comunes del franquismo, según dispone el Tribunal Supremo en el Auto de 28 de marzo de 2012, corresponde a los Juzgados de instrucción de los lugares donde ocurrieron presuntamente los hechos ${ }^{23}$.

Por su parte «Eusko Lurrra Fundazioa», y en referencia a una exhumación realizada en Araba en 2013, dijo: «La exhumación, como por desgracia viene

\footnotetext{
${ }^{22}$ Los análisis genéticos se realizan en el laboratorio Nasertic de Navarra, que se encuentra acreditado para análisis forenses y en el que ya se ha creado un banco de ADN para estos fines.

${ }^{23}$ Federación de Foros por la Memoria, 2017.
} 
siendo habitual, se ha realizado sin seguir un protocolo de exhumación válido para que estos restos y las circunstancias de sus muertes puedan ser utilizadas en una futura causa judicial contra el Franquismo. De esta manera se han perdido para siempre pruebas judiciales y se sigue apuntalando la impunidad franquista». Y proseguía: «Este nuevo caso de manipulación de la memoria histórica engarza con un reciente artículo de opinión de nuestra fundación que refleja certeramente cómo tras un supuesto acto bienintencionado, una exhumación, se puede esconder un auténtico disparate ${ }^{24}$. Esto es, estamos borrando las pruebas de los crímenes.

En este contexto, y para tranquilidad de los más críticos, hay que insistir en que las exhumaciones en Navarra se han efectuado cumpliendo los estándares forenses al uso en el plano técnico y científico y, además, se han llevado a cabo con arreǵlo a la legislación específica establecida al respecto. Si no se pueden discutir los principios de legitimidad y de legalidad que asisten a este tipo de investigaciones, para los que el liderazgo institucional no ha faltado, tampoco creemos que se puedan discutir los procedimientos empleados en lo que respecta a la aplicación de las técnicas forenses utilizadas. Técnicas y procedimientos, tal y como se contempla en el Protocolo de exhumaciones de la Comunidad Foral de Navarra, con los que se han exhumado 59 fosas y recuperado 243 esqueletos, que han sido analizados, estudiados y restituidos a sus familiares si han podido ser identificados (tabla 5) ${ }^{25}$.

Tabla 5. Síntesis de los resultados en la Comunidad Foral de Navarra actualizados a $2020^{26}$. Desde la creación del Instituto Navarro de la Memoria, en 2016, se han exhumado 114 víctimas de las que se han identificado 26 (22\%).

\begin{tabular}{ccccc}
$\begin{array}{c}\text { Fosas intervenidas: } \\
\text { buscadas y prospectadas }\end{array}$ & $\begin{array}{c}\text { Fosas no } \\
\text { encontradas }\end{array}$ & $\begin{array}{c}\text { Fosas } \\
\text { exhumadas }\end{array}$ & $\begin{array}{c}\text { Restos } \\
\text { recuperados }\end{array}$ & $\begin{array}{c}\text { Restos } \\
\text { identificados }\end{array}$ \\
\hline 126 & $67(53 \%)$ & $59(46 \%)$ & 243 & $110(45 \%)$ \\
\hline
\end{tabular}

${ }^{24} \mathrm{http} / /$ www.euskolurra.eu/exhumaciones-en-ǵopeǵi-un-nuevo-ataque-ala-memoria-sociopoliticay-a-los-derechos-verdad-justicia-y-reparacion-de-las-victimas-del-franquismode. Lo que no impidió que la coordinadora Lau Haizetara Gogoan solicitara a Francisco Etxeberria un informe pericial en relación a las causas de muerte de las personas cuyos restos humanos habían sido recuperados desde el año 2000 en fosas comunes de la Guerra Civil (1936-1939) y en el que se aporta como anexo el ejemplo de la exhumación de la fosa de Tudela del año 2010.

${ }^{25}$ Herrasti y Etxeberria, 2019a y 2019b.

${ }^{26}$ El censo de víctimas establecido en la Oficina de Víctimas del Ministerio de Justicia en 2011 arrojaba la cantidad de 77 fosas en Navarra de las que 11 habrían sido trasladadas al Valle de los Caídos. 
Pero todavía podemos ir más lejos. Las investigaciones forenses realizadas tampoco han sido descalificadas en las instancias internacionales como en el caso de la Querella Arǵentina contra los crímenes del franquismo (CEAQUA) iniciada en 2010, en la que presentamos un informe pericial con varios ejemplos y que todavía no se ha resuelto, así como en las demandas presentadas ante el Tribunal Europeo de Derechos Humanos en el que se produjo, en 2012, la desalentadora resolución de la inadmisibilidad a trámite del primer ejemplo analizado relativo a la desaparición de Luis Dorado Luque, y no por las cuestiones forenses relativas a este caso ${ }^{27}$.

Y finalmente, ¿qué pasaría si, como lo han reivindicado algunas asociaciones de memoria histórica, se pusiera en marcha una comisión sobre la verdad? ${ }^{28}$ La respuesta es muy clara: todo lo actuado en la Comunidad Foral de Navarra sería validado y asumido bajo el argumento de la formalidad y la legalidad del proceso seguido.

\section{Navarra: tres tipologías de víctimas y un mismo modelo de intervención forense}

De conformidad a los casos investigados desde la perspectiva forense, entre el año 2005 y 2020, se pueden establecer tres categorías de víctimas de la represión franquista con resultado de muerte:

a) Ejecuciones extrajudiciales, que representan el grueso de los crímenes.

b) Muertes en cautividad, por la relevancia de la prisión del Fuerte de San Cristóbal. En este apartado se incluyen las ejecuciones extrajudiciales de presos fugados de dicha cárcel el 22 de mayo de 1938.

c) Persecución al maquis y a la lucha guerrillera en la postǵuerra.

${ }^{27}$ Luis Dorado Luque fue un médico y político socialista fusilado en Córdoba en 1936. El Tribunal de Estrasburgó señala que la reclamación de los demandantes se refiere a unos hechos que ocurrieron mucho tiempo antes de la adopción de la Convención Europea de Derechos Humanos el 4 de noviembre de 1950 y su ratificación por España el 4 de octubre de 1979. Un amplio análisis del caso se encuentra en Galella, 2014.

28 Así la «Plataforma para la comisión de la verdad sobre los crímenes del franquismo» (https:// comisionverdadfranquismo.com/manifiesto-de-las-victimas/) lo viene reivindicando desde el año 2013 y Amnistía Internacional desde el 2006 en su informe «Víctimas de la guerra civil y el franquismo: no hay derecho». 


\subsection{Las ejecuciones extrajudiciales}

Mejor calificadas como asesinatos, conforman el volumen principal y muy específico de los crímenes en Navarra. Fueron actos de represión de retaguardia en un territorio en el que no se produjeron episodios de guerra. Esta tipología se corresponde con delitos de lesa humanidad si tenemos en cuenta que fueron personas detenidas y hechas desaparecer, lo que conlleva una metodología de análisis específica desde las recomendaciones de Naciones Unidas.

Dependiendo de algunas características propias de las víctimas, estas ejecuciones extrajudiciales se pueden clasificar en «grupos cerrados» en los que $a$ priori se conoce las identidades de las víctimas, o «grupos abiertos» en los que se ignora esta circunstancia y resulta más difícil el proceso de identificación, dado que los análisis antropolóǵicos pueden orientar las investigaciones, pero precisan ser confirmados genéticamente.

Algúno de los ejemplos claros de grupo cerrado puede ser el de Fustiñana, en el que, según la documentación recopilada por Lara Bartos, siete vecinos de Murchante fueron detenidos el 20 de noviembre de 1936 y conducidos a la cárcel de Tudela. De aquí fueron sacados para ser asesinados en el lugar denominado La Corraliza de Fustiñana. Las labores de búsqueda y prospección de la fosa resultaron algo arduas, pero, con la información concreta aportada por un vecino, se consiguió localizar el emplazamiento. En este caso, la identificación de las víctimas se estimó a partir de las características antropológicas de edad y las condiciones de patología. Se pudo establecer la identidad de todas ellas: Hilario Chueca Ayala, Roque Jarauta Chueca, Genaro Ochoa Lorente, Julio Orta Simón, Antonio Pérez Ullate, Ricardo Rosel Aguirre y Mauricio Simón Arriazu ${ }^{29}$.

Otro caso similar sería la fosa de Aibar en la que se recuperaron los restos de cuatro vecinos de Cáseda, enterrados en el paraje de Fuente del Garrero. En este caso, la estimación identificativa a través del análisis antropológico se confirmó mediante pruebas genéticas que determinaron la identidad de tres de ellos ${ }^{30}$.

Otras veces se conoce y se comprueba la existencia de fosas en un lugar, pero se carece de información sobre la condición e identidad de las víctimas. Eso ocurre en el caso de las cuatro fosas del paraje de Iruzkun (Ollacarizqueta), en las que se hallaban inhumadas veinte personas. Se cree que fueron trasladadas a este sitio por un grupo de victimarios desde un lugar donde estaban previamente detenidas.

\footnotetext{
${ }^{29}$ Etxeberria y Herrasti, 2017.

${ }^{30}$ Etxeberria et al., 2012.
} 
Las fosas citadas se encontraban en zonas apartadas de manera clandestina, pero muchas víctimas también se enterraron en cementerios como el de Tudela, en donde tras ser asesinados fueron enterrados, entre otros, dos vecinos de Ablitas: Hiǵinio Arriazu Ruiz y Bonifacio García Enciso. Por el registro del libro del cementerio se conocía la inscripción de estas dos víctimas en un lugar concreto ${ }^{31}$, además de varios vecinos originarios de Alfaro que fueron exhumados a finales de la década de los 70. En el cementerio de Urzante fueron inhumados varios grupos de víctimas trasladadas de distintos pueblos próximos de la provincia de Zaragoza, como Novallas, Vera de Moncayo, Vierlas o Tarazona ${ }^{32}$.

El hecho de que los enterramientos se encuentren en cementerios parece facilitar las labores forenses, pero, en realidad, puede ocurrir todo lo contrario, ya que la reutilización del espacio funerario a lo largo del tiempo ha alterado su emplazamiento y modificado sustancialmente las evidencias.

Otros ejemplos que parecen bastante específicos de Navarra, en lo referente al objetivo de ocultar los cadáveres con el fin de dificultar su localización, han sido las simas a las que fueron arrojados un número importante de cuerpos. Así cabe mencionar las emblemáticas simas de Otsoportillo y El Raso en Urbasa, y Legarrea en Gaztelu ${ }^{33} \ldots$

Efectivamente, estas intervenciones forenses representan una enorme complejidad técnica, pero, gracias a equipos de intervención preparados y al uso de medios técnicos profesionales, se han obtenido algunos resultados extraordinarios. La sima de El Raso es una de las citadas por Jimeno Jurío y Altaffaylla como cavidad donde se arrojaron los cuerpos de varias víctimas tras su asesinato. La exhumación, promovida por Balbino García de Albizu, como familiar, y la asociación de familiares AFFNA36, se llevó a cabo en marzo de 2013. El emplazamiento de la entrada de la sima estaba señalizado por una estela con nombres de tres de las víctimas y una placa de hormigón sellaba la boca de entrada. Dentro de la cavidad y bajo la vertical del acceso existía un cono de derrubios y en la base de este se distribuían los restos óseos humanos. Los cadáveres habían sido precipitados desde la boca y se deslizaron hasta la parte más inferior de la cavidad. Se recuperaron los restos de diez personas que superaban la cifra de víctimas conocida por fuentes orales y documentales. De este modo se elaboró una relación de las posibles víctimas, se obtuvieron las muestras genéticas de familiares y se realizaron las pruebas de comparación logrando la identificación de nueve de las diez víctimas ${ }^{34}$.

\footnotetext{
${ }^{31}$ Etxeberria et al., 2010.

32 Etxeberria y Herrasti, 2017.

${ }^{33}$ Etxeberria, Serrulla y Herrasti, 2014.

${ }^{34}$ Herrasti et al., 2015.
} 
Un caso muy especial de ocultamiento de los cuerpos lo representa la sima de Legarrea. La historia de la desaparición de una madre y sus seis hijos aparecía referida en las narraciones de la Guerra Civil con una cierta imprecisión. Tras varias vicisitudes y contando con la necesaria autorización judicial, los restos fueron localizados a 45 metros de profundidad, verificando así la muerte por asesinato de Juana Josefa Goñi Sagardia, de 38 años, y la de sus hijos: Joaquín, de 16 años; Antonio, de 12; Pedro Julián, de 9; Martina, de 6; José, de 3, y Asunción, de 18 meses.

\subsection{Muertes en cautividad}

Las precarias e insalubres condiciones de frío, humedad y hacinamiento provocaron un importante índice de mortalidad entre el ingente número de personas presas en la Prisión de San Cristóbal de Pamplona. En 1941 la cárcel se convirtió en sanatorio penitenciario antituberculoso, donde la enfermedad provocaba un alto número de muertes. Los presos fallecidos eran enterrados en los cementerios de la Cendea de Ansoáin, pero en mayo de 1942 se construyó un cementerio de uso exclusivo en la ladera del monte Ezkaba. La Asociación Cultural Txinparta pidió la colaboración de la Sociedad de Ciencias Aranzadi para iniciar la tarea de exhumación del cementerio de la Prisión de San Cristóbal en 2007. Ese año se expusieron cinco tumbas, pero lo que se encontró no se ajustaba a lo esperado, pues no existía coincidencia entre la documentación y los restos hallados. En 2010 se optó por exponer toda la extensión del cementerio y comprender la disposición de las tumbas en relación al croquis elaborado por el capellán de la prisión, con las referencias a la identificación de las personas presas que estaban enterradas en cada una de las tumbas. Se supo quién estaba enterrado en cada tumba. Asimismo, se comprobó que la denominación de Cementerio de las Botellas respondía al hecho de que en cada tumba existía una botella, con el documento de filiación del fallecido, cumpliendo así la orden dictada por el Generalísimo Franco de enero de $1937^{35}$.

En el cementerio existían 131 tumbas utilizadas, distribuidas en cuatro filas. Se enterró siguiendo un orden correlativo, de mayo de 1942 a junio de 1945, a

${ }^{35}$ En el monográfico titulado «El Fuerte de San Cristóbal en la memoria: de prisión a sanatorio penitenciario. El cementerio de las botellas» (Etxeberria y Pla, 2014), se recoge todo el proceso de documentación, exhumación, análisis de los restos óseos, fichas individualizadas de las 45 víctimas exhumadas por solicitud de los familiares, identificación, estudio de los ǵrafitis en las paredes de la prisión, además de la descripción y análisis detallado de las botellas recuperadas en el proceso de excavación. 
excepción de los presos que renunciaban a la confesión y se inhumaron en el espacio civil. Las tumbas tenían el mismo formato y dimensión, pues los fallecidos eran introducidos en ataúdes trapezoidales de madera de pino de medidas estándar. Entre las extremidades inferiores de cada inhumado se hallaba una botella de cristal con el documento con la identidad del difunto. El hallazgo de algunos de los documentos intactos permitió corroborar la distribución exacta de las tumbas en el cementerio.

Se exhumaron 45 tumbas cuyos restos fueron analizados y estudiados para, posteriormente, ser restituidos a sus respectivos familiares.

\subsubsection{Persecución de los presos fugados el 22 de mayo de 1938 de la prisión del Fuerte de San Cristóbal}

Una especificidad de esta tipología de muertes en cautividad la constituye en Navarra lo referente a los asesinatos, nuevamente muertes extrajudiciales, de los presos fugados de esta prisión.

El 22 de mayo de 1938 un total de 795 presos se fugaron de la prisión de San Cristóbal. Su intención era alcanzar la frontera y huir a Francia. Sin embargo, la señal de alarma dada por los militares cuando detectaron la fuga se transmitió rápidamente a las dependencias de la Guardia Civil, que estableció una extensa red de vigilancia con la implicación de los vecinos de los pueblos situados en las rutas de salida hacia el norte. De esa manera fueron interceptados la mayor parte de ellos. Solo tres o cuatro consiguieron atravesar la frontera. Muchos fugados fueron detenidos y trasladados de nuevo a la prisión. Sin embargó, a lo largó de los siguientes días, 206 presos fueron apresados y ejecutados en el lugar donde fueron capturados.

Los presos fugados tendieron, de manera improvisada, a escapar en grupos pequeños en un intento instintivo de pasar más desapercibidos. Muchas veces, se movían de noche, trataban de evitar los caminos más concurridos. Por esta razón el número de personas es reducido en las fosas localizadas, normalmente, inferior a cuatro. Son excepciones los casos de Burutain (Anué), Urtasun (Esteribar) y, particularmente, Olabe (Olaibar), en los que la cifra fue mayor porque concentraron un grupo de dieciséis que retuvieron durante una noche hasta conocer cuáles iban a ser las órdenes. De los 206 presos fugados, que fueron ejecutados y enterrados de forma clandestina, se han recuperado 54 en 13 fosas (tabla 6).

Citamos como ejemplo la fosa de Elia (Valle de Egüiés) que fue la primera de este tipo exhumada. De los distintos itinerarios que los presos tomaron para llegar a territorio francés, varios de los fugados se adentraron en el Valle de Egüiés. 
Algunos vecinos de Elia, dirigidos por la Guardia Civil de Villaba, hacían guardia con escopetas a la espera de arrestar a los fugados. En este pueblo detuvieron a cuatro. Era la tarde del día 22 de mayo. Avisaron al cura para que confesara a los detenidos. Uno consiguió zafarse y escapar, pero los otros tres fueron asesinados. Fueron enterrados en dos fosas, una individual con el cuerpo en posición decúbito prono, la otra fosa era doble y los dos estaban maniatados. El cura de Ibiricu que les confesó, natural de Vidángoz/Bidankoze, reconoció a uno de los fugados como su convecino Vicente Mainz Landa. Las pruebas genéticas confirmaron su identidad.

Tabla 6. Fosas en las que se han recuperado restos de los fugados de la prisión de San Cristóbal

\begin{tabular}{|c|c|c|c|}
\hline \multicolumn{4}{|c|}{ Fosas de fugados el 22 de mayo de 1938} \\
\hline Fosa & Municipio & Año exhumación & $\mathrm{N}^{o}$ individuos \\
\hline Berriozar (La Esparzeta) & Berriozar & 2015 & 4 \\
\hline Burutain & Anué & 2017 & 6 \\
\hline Elia & Valle de Egüués & 2015 & 3 \\
\hline Larrasoaña & Esteribar & 2018 & 4 \\
\hline Leranotz & Esteribar & 2018 & 2 \\
\hline Lintzoain & Erro & 2017 & 2 \\
\hline Olabe & Olaibar & 2016 & 16 \\
\hline Olabe II & Olaibar & 2018 & 1 \\
\hline Urdaniz & Esteribar & 2018 & 3 \\
\hline Urtasun & Esteribar & 2017 & 5 \\
\hline Usetxi & Esteribar & 2016 & 3 \\
\hline Etulain & Anué & 2018 & 3 \\
\hline Sima Ardaitz & Erro & 2019 & 2 \\
\hline $\mathrm{N}^{\circ}$ de fosas: 13 & & & 54 \\
\hline
\end{tabular}




\subsection{Enterramientos de maquis}

Durante la posguerra los guerrilleros o maquis combatieron contra la dictadura franquista, conformando grupos de acción rápida que se refugiaban en zonas de montaña. Muchos de ellos habían participado en la resistencia en Francia y en su mayoría eran de ideología comunista. Sin embargoo, en España fueron calificados como bandoleros o bandidos y contra ellos se dirigíó una dura política de persecución y represión desde 1940 a 1951. En lo que respecta al maquis en el área de Navarra, Rodríguez ha publicado una monografía concreta ${ }^{36}$.

En el año 2020 se ha intervenido en cinco fosas en las que se han exhumado los restos de seis guerrilleros. Se trataba de personas que se habían adentrado en territorio navarro, procedentes de Francia, y que fueron perseguidos y asesinados en enfrentamientos con la Guardia Civil y el Ejército.

En la localidad de Goldaratz (Imoz) los cuerpos de dos guerrilleros fueron enterrados por los vecinos en emplazamientos distintos. Uno de ellos fue exhumado en el paraje de Etxeberrialde, en el lugar que había sido utilizado como base de una txondorra. Esta peculiaridad se repitió en la otra fosa de Lizardiaundi, también en Goldaratz.

$\mathrm{Al}$ cementerio de Castillonuevo/Gazteluberri fueron trasladados los cadáveres de dos maquis que resultaron muertos en la zona de Ollate. En el camposanto de Sigüiés (Zaragoza) fueron inhumados en dos momentos distintos los cuerpos de dos maquis que murieron en 1948, en el intento de cruzar el río Araǵón. Estas han sido las últimas fosas exhumadas en 2020 en Navarra.

\section{Evolución diacrónica de las exhumaciones en Navarra}

En la siguiente tabla se resumen las intervenciones realizadas y el número de individuos recuperados en cada una de las fosas (tablas 7, 8, 9 y gráficas 1, 2, $3,4,5)$ :

${ }^{36}$ Rodríguez, 2018. 
Tabla 7. Relación cronológica de las exhumaciones realizadas en Navarra en el periodo 2005-2020

\begin{tabular}{|c|c|c|c|}
\hline Año & $\begin{array}{l}\mathrm{N}^{\circ} \text { fosas/tumbas individuales } \\
\text { o fosas diferenciadas }\end{array}$ & $\mathrm{N}^{\circ}$ individuos & Fosas \\
\hline 2005 & 1 & 7 & Fustiñana \\
\hline 2006 & - & - & \\
\hline 2007 & $1 / 5$ & 5 & Cementerio Ezkaba. 5 tumbas \\
\hline 2008 & - & - & \\
\hline 2009 & 1 & 1 & Roncal \\
\hline 2010 & $6 / 43$ & 47 & $\begin{array}{l}\text { Ezkaba: } 37 \text { tumbas, Añezcar (1), } \\
\text { Berriosuso (1), Oteiza de Berrioplano } \\
\text { (2), Aibar (4), Tudela } 1 \text { (2) }\end{array}$ \\
\hline 2011 & 8 & 21 & Urzante en 8 fosas. \\
\hline 2012 & 8 & 29 & $\begin{array}{l}\text { Antxoritz (6), Bera } 1 \text { y } 2 \text { (7), El Raso de } \\
\text { Urbasa (10), Tudela } 2 \text { (2), Tudela } 3 \text { (1), } \\
\text { Ripa (1), Ezkaba (2 tumbas) }\end{array}$ \\
\hline 2013 & 1 & 1 & Ezkaba último \\
\hline 2014 & 1 & 1 & Peralta \\
\hline 2015 & $4 / 9$ & 17 & $\begin{array}{l}\text { Berriozar (4), Elia (3), Lecáun (3), Ibero } \\
\text { ( } 7 \text { en } 6 \text { fosas) }\end{array}$ \\
\hline 2016 & 5 & 41 & $\begin{array}{l}\text { Sima Legarrea (7), Olabe (16), } \\
\text { Otsoportillo (9), Usetxi (3), Cáseda (6) }\end{array}$ \\
\hline 2017 & 5 & 17 & $\begin{array}{l}\text { Artazu (2), Burutain (6), Lintzoain (2), } \\
\text { Otsoportillo } 2 \text { (2), Urtasun (5) }\end{array}$ \\
\hline 2018 & $9 / 12$ & 24 & $\begin{array}{l}\text { Artaiz (2), Larrasoaña (4), Leranotz (2), } \\
\text { Lizarrusti (1), Olabe } 2 \text { (1), Puente de } \\
\text { los Ladrones (2), Urdaniz (3), Urbicain- } \\
\text { Echálaz (6 en } 4 \text { fosas), Etulain (3) }\end{array}$ \\
\hline 2019 & $6 / 7$ & 26 & $\begin{array}{l}\text { Sima de Ardaitz (2), Echálaz 2-Urbicain } \\
\text { ( } 4 \text { en } 2 \text { fosas), Iruzkun (Ollacarizqueta) } \\
\text { (20 en } 4 \text { fosas) }\end{array}$ \\
\hline 2020 & 5 & 6 & $\begin{array}{l}\text { Gazteluberri (2), Etxeberrialde } \\
\text { (Goldaratz) (1), Lizardiaundi } \\
\text { (Goldaratz) (1), Sig̈üés (Zaragoza) (2 en } \\
2 \text { tumbas) }\end{array}$ \\
\hline Total: & $60 / 111$ & 243 & \\
\hline
\end{tabular}


Francisco Etxeberria / Lourdes Herrasti

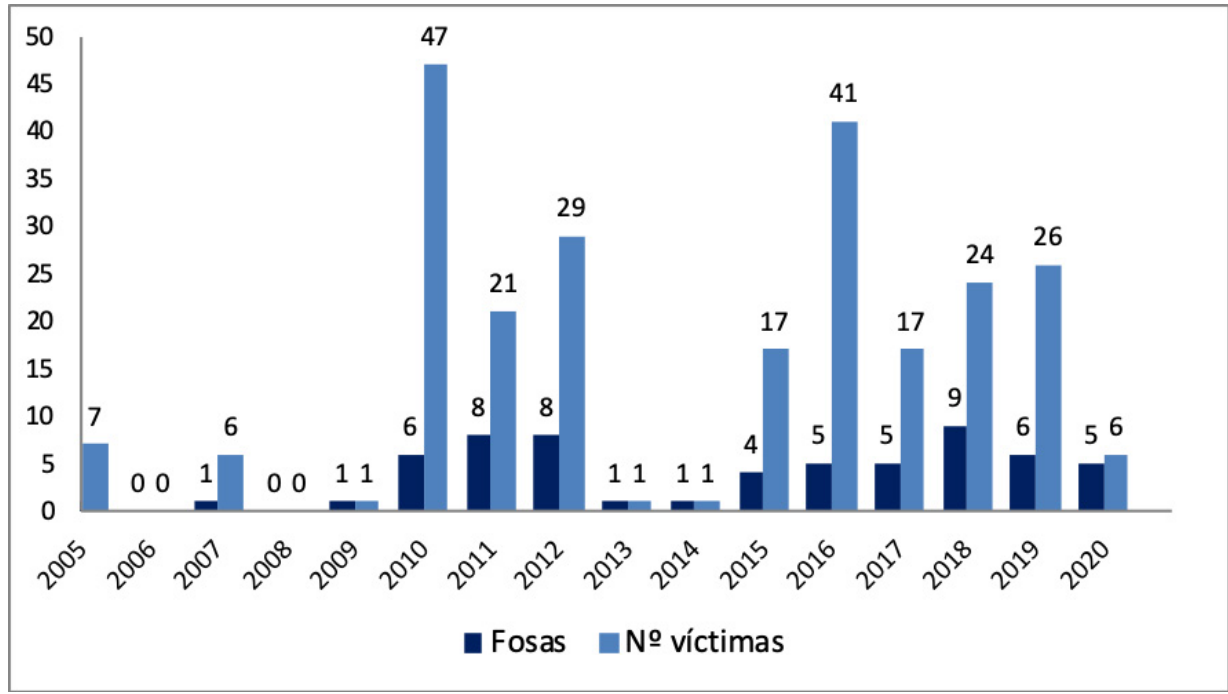

Gráfica 1. Evolución diacrónica de las exhumaciones en Navarra desde 2005 a 2020.

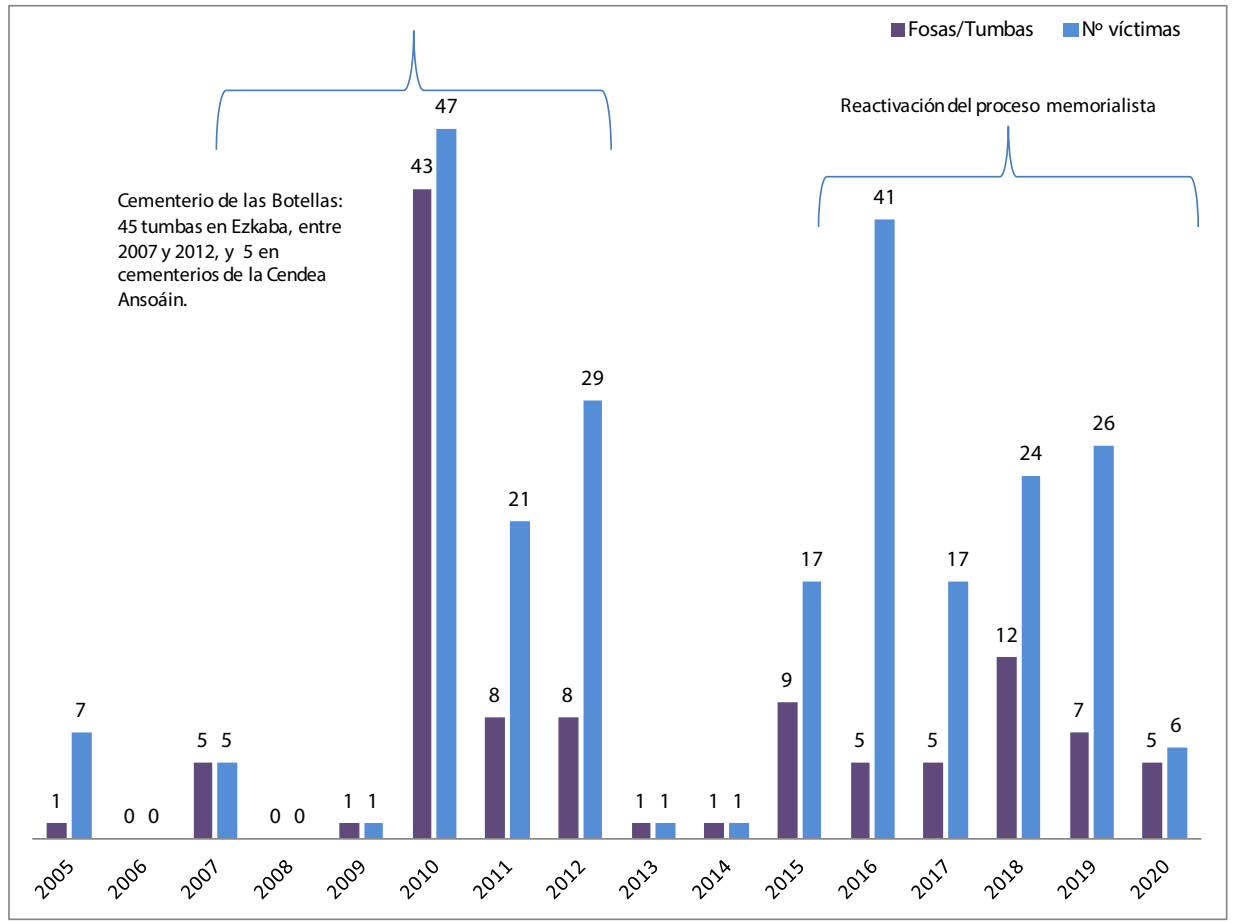

Gráfica 2. Evolución de las exhumaciones en Navarra en la etapa reciente: fases. 


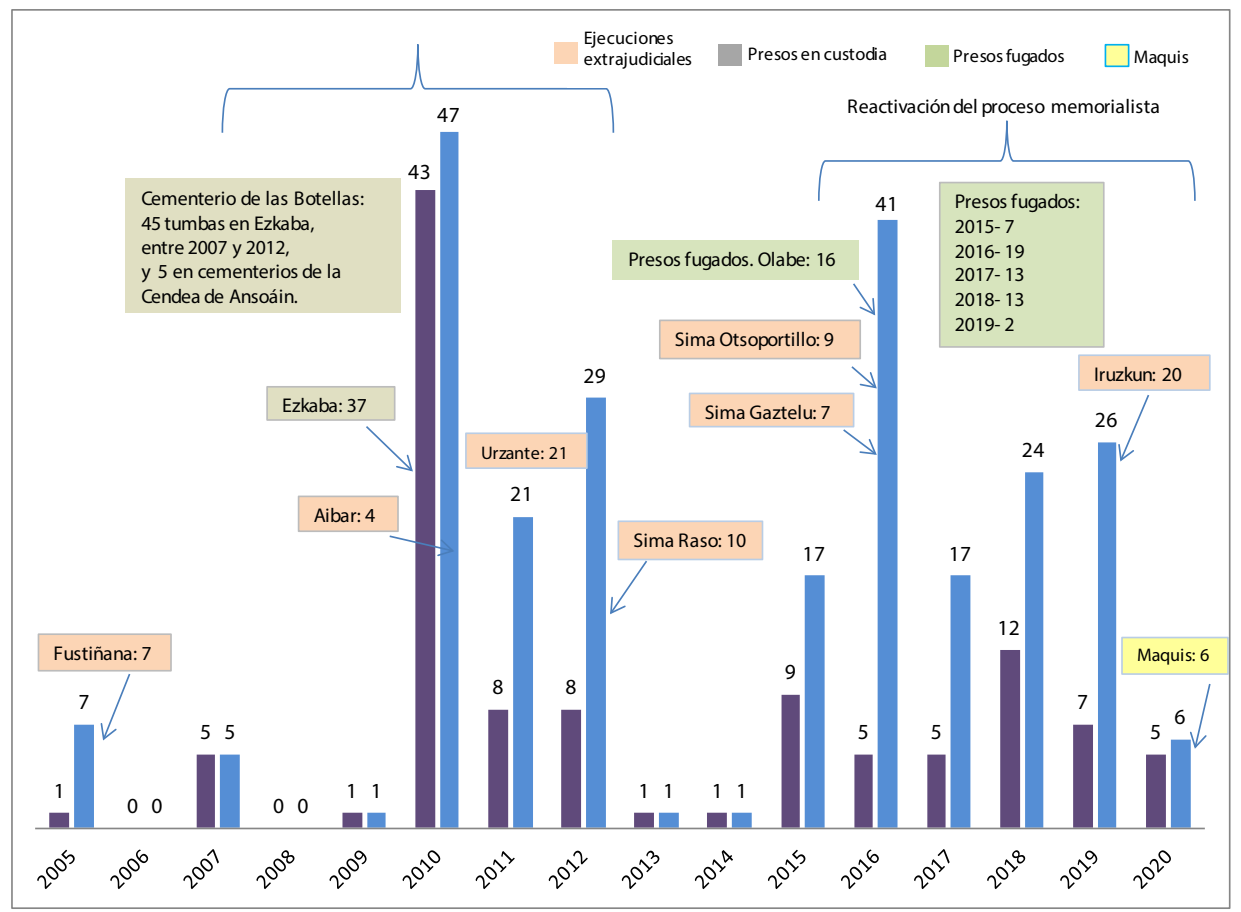

Gráfica 3. Fases con las exhumaciones más destacadas y carácter de las mismas.

Tabla 8. Fosas exhumadas y número de individuos recuperados en Navarra

\begin{tabular}{|lcc|}
\multicolumn{1}{c}{ Tipo de víctima } & $\mathrm{N}^{\mathrm{o}}$ fosas & $\mathrm{N}^{\mathrm{o}}$ individuos \\
\hline Ejecuciones extrajudiciales & $\begin{array}{c}32+3 \text { (sacas) }+ \\
13 \text { (presos fugados) } 48\end{array}$ & $\begin{array}{c}120+13 \text { (sacas) }+ \\
\text { (presos fugados) } 187\end{array}$ \\
\hline Presos en cautividad & 7 & 50 \\
Guerrilleros/maquis & 5 & 6 \\
Total: & 60 & 243
\end{tabular}

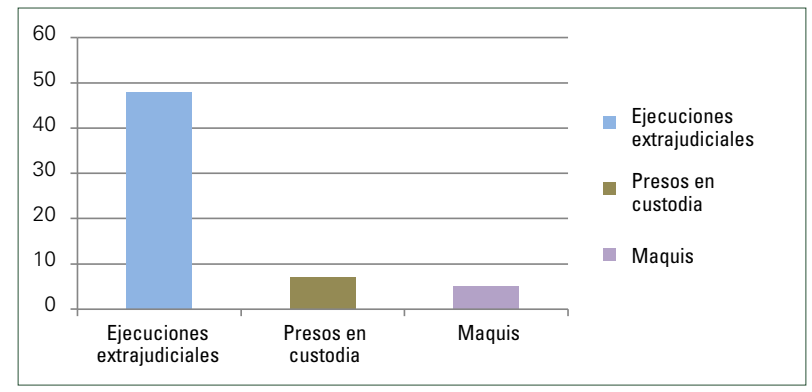

Gráfica 4. Fosas por tipo de víctima. 
Francisco Etxeberria / Lourdes Herrasti

Tabla 9: Fosas exhumadas en relación al tipo de víctima

\begin{tabular}{|c|c|c|c|c|c|c|c|c|c|}
\hline & $\begin{array}{l}\text { Ejecuc } \\
\text { extraju }\end{array}$ & $\begin{array}{l}\text { iones } \\
\text { liciales }\end{array}$ & $\begin{array}{l}\text { Pres } \\
\text { cust }\end{array}$ & $\begin{array}{l}\text { os en } \\
\text { odia }\end{array}$ & $\begin{array}{r}\text { Sacas } \\
\text { pres }\end{array}$ & $\begin{array}{l}\text { s de } \\
\text { sos }\end{array}$ & Presos & ugados & $\begin{array}{l}\text { Guerrilleros/ } \\
\text { Maquis }\end{array}$ \\
\hline & $\mathrm{n}^{\circ}$ fosas & $\mathrm{n}^{\circ}$ ind. & $\mathrm{n}^{\circ}$ fosas & $\mathrm{n}^{\circ}$ ind. & $\mathrm{n}^{0}$ fosas & $\mathrm{n}^{\circ}$ ind. & $\mathrm{n}^{\mathrm{o}}$ fosas & $\mathrm{n}^{\circ}$ ind. & $\mathrm{n}^{\circ}$ fosas $\mathrm{n}^{\circ}$ ind. \\
\hline Fustiñana & 1 & 7 & & & & & & & \\
\hline Ezkaba & & & 45 & 45 & & & & & \\
\hline $\begin{array}{l}\text { Añezcar, Berriosuso } \\
\text { y Oteiza de B. }\end{array}$ & & & 4 & 4 & & & & & \\
\hline Roncal & & & 1 & 1 & & & & & \\
\hline Aibar & 1 & 4 & & & & & & & \\
\hline Tudela 1 & 1 & 2 & & & & & & & \\
\hline Tudela 2 & 1 & 2 & & & & & & & \\
\hline Tudela 3 & 1 & 1 & & & & & & & \\
\hline Urzante & 8 & 21 & & & & & & & \\
\hline Antxoritz & & & & & 1 & 6 & & & \\
\hline Bera & & & & & 2 & 7 & & & \\
\hline Raso Urbasa & 1 & 10 & & & & & & & \\
\hline Ripa & 1 & 1 & & & & & & & \\
\hline Peralta & 1 & 1 & & & & & & & \\
\hline Berriozar & & & & & & & 1 & 4 & \\
\hline Elia & & & & & & & 1 & 3 & \\
\hline Lecáun & 1 & 3 & & & & & & & \\
\hline Ibero & 6 & 7 & & & & & & & \\
\hline Olabe & & & & & & & 1 & 16 & \\
\hline Cáseda & 1 & 6 & & & & & & & \\
\hline Sima Legarrea & 1 & 7 & & & & & & & \\
\hline Sima Otsoportillo & 2 & 11 & & & & & & & \\
\hline Usetxi & & & & & & & 1 & 3 & \\
\hline Artazu & 1 & 2 & & & & & & & \\
\hline Burutain & & & & & & & 1 & 6 & \\
\hline Lintzoain & & & & & & & 1 & 2 & \\
\hline Urtasun & & & & & & & 1 & 5 & \\
\hline Artaiz & 1 & 2 & & & & & & & \\
\hline Larrasoaña & & & & & & & 1 & 4 & \\
\hline Leranotz & & & & & & & 1 & 2 & \\
\hline Olabe 2 & & & & & & & 1 & 1 & \\
\hline Puente Ladrones & 1 & 2 & & & & & & & \\
\hline Urdaniz & & & & & & & 1 & 3 & \\
\hline Urbicain-Echálaz & 4 & 6 & & & & & & & \\
\hline
\end{tabular}




\begin{tabular}{|c|c|c|c|c|c|c|c|c|c|c|}
\hline & \multicolumn{2}{|c|}{$\begin{array}{c}\text { Ejecuciones } \\
\text { extrajudiciales }\end{array}$} & \multicolumn{2}{|c|}{$\begin{array}{l}\text { Presos en } \\
\text { custodia }\end{array}$} & \multicolumn{2}{|c|}{$\begin{array}{l}\text { Sacas de } \\
\text { presos }\end{array}$} & \multicolumn{2}{|c|}{ Presos fugados } & \multicolumn{2}{|c|}{$\begin{array}{l}\text { Guerrilleros/ } \\
\text { Maquis }\end{array}$} \\
\hline & $\mathrm{n}^{\circ}$ fosas & $\mathrm{n}^{\circ}$ ind. & $\mathrm{n}^{\circ}$ fosas & $\mathrm{n}^{\circ}$ ind. & $\mathrm{n}^{\circ}$ fosas & $\mathrm{n}^{\circ}$ ind. & $\mathrm{n}^{\circ}$ fosas & $\mathrm{n}^{\circ}$ ind. & $\mathrm{n}^{\circ}$ fosas & $\mathrm{n}^{\circ}$ ind. \\
\hline Lizarrusti & 1 & 1 & & & & & & & & \\
\hline Echálaz 2 & 2 & 4 & & & & & & & & \\
\hline Etulain & & & & & & & 1 & 3 & & \\
\hline Sima Ardaitz & & & & & & & 1 & 2 & & \\
\hline Iruzkun & 4 & 20 & & & & & & & & \\
\hline Gazteluberri & & & & & & & & & 1 & 2 \\
\hline Etxeberrialde & & & & & & & & & 1 & 1 \\
\hline Lizardiaundi & & & & & & & & & 1 & 1 \\
\hline Siǵüés (Zaragoza) & & & & & & & & & 2 & 2 \\
\hline Total: & 40 & 120 & 50 & 50 & 3 & 13 & 13 & 54 & 5 & 6 \\
\hline
\end{tabular}

\section{Conclusiones: perfil de las víctimas}

Se han recuperado un total de 243 víctimas en 60 fosas, de las que 50 son tumbas individuales de presos fallecidos en cautividad (gráfica 5).

El $49 \%$ de las mismas corresponden a víctimas civiles ejecutadas. Se trata de personas que fueron detenidas en sus casas o lugares de trabajo y que fueron trasladadas a los puntos donde fueron asesinadas y enterradas de forma clandestina. A los anteriores se suman las personas que fueron asesinadas tras ser excarceladas, con un $5 \%$, y la persecución y ejecución de presos fugados, con un $22 \%$, lo que asciende a $76 \%$ el porcentaje de ejecuciones extrajudiciales. Fueron hechos desaparecer porque no dejaron rastro del luǵar de entierro, ni de su localización, ni fueron inscritos en el Registro Civil. Responden a la categoría de víctimas de desaparición forzada.

Así ocurrió en las fosas de Fustiñana, Aibar, Urzante, Raso de Urbasa, sima de Otsoportillo, sima de Gaztelu... Todos ellos serían ejemplo de las más de 3000 víctimas de represión de retaguardia que se produjeron en los meses de julio a octubre de 1936, durante el periodo del llamado terror caliente. También en este periodo se sucedieron las excarcelaciones o sacas de personas detenidas desde las cárceles de Pamplona, de la prisión provincial o de las cárceles instaladas en los conventos de Escolapios y Agustinos, a los que se habría que sumar las cárceles comarcales de Estella, Tafalla..., además del traslado de varios grupos desde la prisión de Ondarreta de Donostia (Gipuzkoa) para ser asesinados en Bera.

Aunque en el resto del Estado este tipo de víctimas suponen el 89\%, conviene tener en cuenta que en Navarra en la etapa de la Transición se realizaron un gran 
número de exhumaciones y entonces fueron recuperados y restituidos un gran porcentaje de las víctimas. Las exhumaciones de este periodo fueron llevadas a cabo por familiares y vecinos de los desaparecidos, coordinados por autoridades municipales y sacerdotes, siguiendo la labor de documentación de José $\mathrm{M}^{\mathrm{a}}$ Jimeno Jurío, que han sido tratadas en las investigaciones desarrolladas por Aguilar y Kerangat $^{37}$.

El segundo grupo está compuesto por muertos en cautividad. La exhumación del cementerio de Ezkaba es uno de los mejores exponentes de presos fallecidos en cautiverio que se ha exhumado. Otros ejemplos son Valdenoceda (Burgos), Uclés (Cuenca) o en las prisiones y campos de concentración de Castuera (Badajoz) u Orduña (Bizkaia).

El rasgo diferencial de la recuperación de la memora histórica en Navarra está en la existencia de fosas de presos fugados. La mayor parte de los arrestados fueron devueltos a la prisión, pero un total de 206 fueron asesinados en el lugar donde fueron interceptados. Se trata de un número de fosas elevado porque los grupos de fugados estaban compuestos por un número reducido, inferior a los seis integrantes.

Si para el conjunto del Estado el porcentaje de víctimas de sexo femenino hallado en las fosas oscila entre el 2 y el $3 \%$, en Navarra, sin embargo, se conocen pocos casos de mujeres enterradas en fosas. En el trabajo de Altaffaylla se mencionan 34 mujeres asesinadas. Entre otras, se sabe que en la fosa de La Tejería de Monreal fue inhumada una maestra con el grupo de Peralta el 26 de octubre de 1936. En la fosa de Echálaz estaba enterrada una vecina de Caparroso llamada Matilde Ruiz Remón. Amada Morentín Roldán, vecina de Lodosa, fue enterrada en la fosa de Ilkai (Ibiricu, Valle de Yerri). Tras el asesinato de Maravillas Lamberto, de Larraga, su cadáver fue quemado para ocultar y borrar los ultrajes contra ella cometidos. La maestra de Güesa (Valle de Salazar), Camino Oscoz Urriza, fue detenida, rapada, exhibida en público, vejada y humillada. La trasladaron a la sierra de Urbasa y, posiblemente, precipitaron su cadáver en el Balcón de Pilatos, para que no quedaran pruebas del delito.

Solo una de las personas víctima de asesinato recuperada en las exhumaciones recientes es de sexo femenino. Se trata de Juana Josefa Goñi Sagardia, que desapareció con sus seis hijos más jóvenes de la localidad de Gaztelu (Donamaria), y que a finales del mes de agosto de 1936 habían sido arrojados a la sima de Legarrea. La desaparición efectiva de esta familia y la crueldad del hecho de que fueran asesinadas con absoluta impunidad niños de 16, 12, 9, 6 y 3 años, además de una niña de 18 meses, pasó a convertirse en una leyenda, que por su brutalidad resultaba inconcebible. El hallazgo de los restos de los siete miembros de la familia ha servido para levantar la losa del silencio sobre un gran secreto en la comarca.

${ }^{37}$ Aguilar, 2019; Kerangat, 2020. 
El 50\% de las víctimas represaliadas eran labradores, jornaleros o agosteros. En Navarra existía una gran desigualdad en la distribución de la tierra. Los trabajadores del campo solicitaban una mejora en las relaciones laborales, la distribución de las corralizas y un mejor reparto del aprovechamiento de las tierras del comunal. Esta situación había motivado que muchos trabajadores del campo se afiliaran a sindicatos, particularmente a UGT, pero también a CNT. Contra ellos se dirigió y planificó una dura represión. Casi todas las víctimas que se hallaban en las fosas de Fustiñana, Aibar y El Raso de Urbasa pertenecían a UGT, o apoyaban partidos de izquierda como Izquierda Republicana.

Entre las víctimas exhumadas hay varios cargoos públicos. En el informe sobre «Cargóos públicos navarros asesinados como consecuencia de la sublevación militar de $1936 »^{38}$, se establece una clasificación en tres grupos en función del ámbito de actuación del cargo: municipal, foral o estatal.

Así se han recuperado los restos pertenecientes a cargós municipales en las fosas del Alto de las Tres Cruces de Ibero, donde se hallaban dos concejales del Ayuntamiento de Pamplona: José Roa García y Gregorio Ángulo Martinena. Este último había sido fundador y presidente de UGT en Navarra. También en Ibero, estuvo, aunque no se ha podido confirmar genéticamente, Silverio Astiz, que en 1936 era alcalde de Etxarri-Aranatz. De este pueblo eran los miembros de la junta local de UGT, cinco de las víctimas cuyos cuerpos fueron precipitados en la sima de El Raso de Urbasa.

En lo que respecta a la distribución geográfica de la represión, esta fue muy intensa en la Ribera o en el tercio meridional de Navarra. El 59\% de los asesinatos tuvieron lugar en la Ribera ${ }^{39}$, donde se concentraban las fosas con mayor número de personas. Sin embargo, las autoridades locales, en cada caso, fueran estas políticas, sociales o religiosas, moderaron o acentuaron la acción de esa represión.

Durante los años 1978 y 1979 se exhumaron de manera sucesiva numerosas fosas que estaban situadas en la Ribera, donde la represión fue mayor, y la necesidad social de recuperación de los restos y de su memoria fue más irrefrenable. Se trataba de fosas exhumadas con mayor número de víctimas, como: La Castellana, Milagro, Pitillas, El Mallatón... Algoo similar ocurrió en la zona oriental de Navarra con las fosas de La Tejería de Monreal o Sengáriz.

Sin embargo, las fosas que se han exhumado de 2005 a 2020 se sitúan preferentemente en la zona central, en la Cuenca de Pamplona (fosas de Ibero o Iruzkun), y, sobre todo, en la mitad septentrional de Navarra, en el área geográfica al norte de Pamplona con las fosas de presos (Ezkaba, Antxoritz, Bera) y de presos fugados.

\footnotetext{
38 Majuelo et al., 2016.

${ }^{39}$ De las 2875 víctimas recogidas por Altaffaylla, 859 en Ribera occidental, 363 en la Ribera central y 456 en la Ribera tudelana. Mikelarena, 2009.
} 


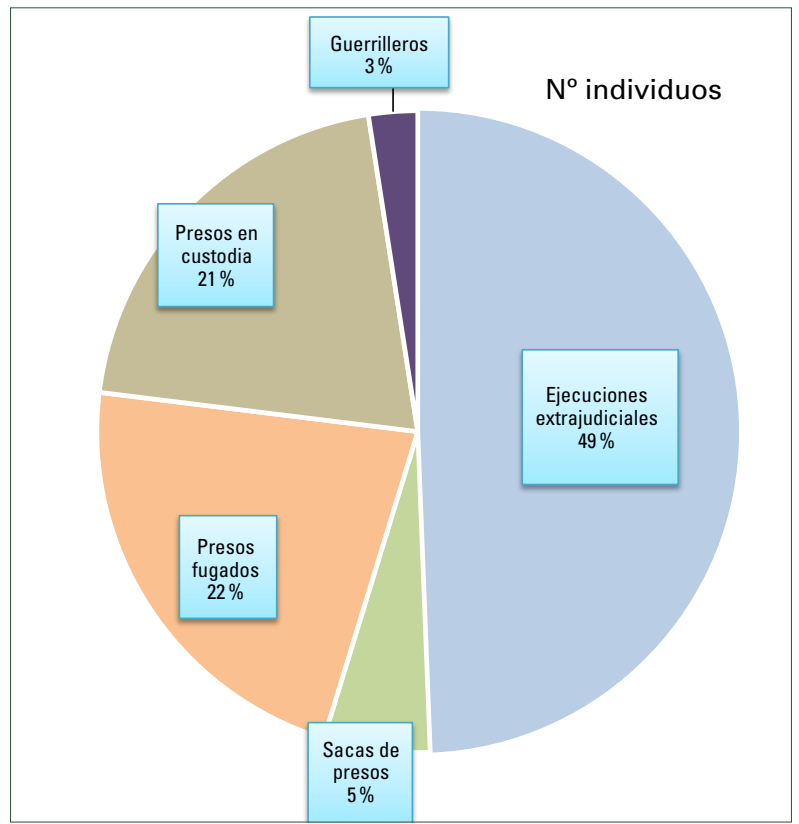

Gráfica 5. Fosas exhumadas y número de individuos recuperados en función del tipo de víctima.

\section{Bibliografía}

Aguilar, Paloma, «40 años exhumando fusilados del franquismo», Contexto y acción, 203, 2019, https://etxt.es/es/20190109/Politica/23785/memoria-guerra-civil-navarra-republicanos-paloma-aguilar.htm.

Alonso, Antonio et al., «La identificación genética de víctimas de la Guerra Civil Española: la experiencia del Instituto Nacional de Toxicología y Ciencias Forenses», Boletin Galego de Medicina Legal e Forense, 18, 2012, pp. 117-123.

Babiano, José et al., Verdugos impunes. El Franquismo y la violación sistemática de los Derechos Humanos, Barcelona, Pasado y Presente, 2018.

Capellà i Roiǵ, Margalida, "Las "desapariciones forzadas" en España durante la guerra civil y el franquismo: violaciones y crímenes de derecho internacional sin castigo ni reparación», en Juan Soroeta Liceras (ed.), Conflictos y protección de derechos humanos en el orden internacional. Cursos de Derechos Humanos de Donostia-San Sebastián, Universidad del País Vasco, 2006, vol. 6, pp. 265-303.

Cuesta, José Luis de la, y Miren Odriozola, «Mareo normativo de la memoria histórica en España: legislación estatal y autonómica», Revista Electrónica de Ciencia Penaly Criminología, 20, 2018, pp. 1-38, http://criminet.ugr.es/reepc/20/recpe20-08.pdf. 
Espinosa, Francisco, y José Luis Ledesma, «La violencia y sus mitos», en Ángel Viñas Martín (coord.), En el combate por la historia: la República, la Guerra Civil, el Franquismo, Barcelona, Pasado y Presente, 2012, pp. 475-498.

Escudero Alday, Rafael, y Carmen Pérez González, Desapariciones forzadas, represión política y crímenes del franquismo, Madrid, Trotta, 2013.

Etxeberria, Francisco (coord.), Las exhumaciones de la Guerra Civil y la dictadura franquista (2000-2019). Estado actual y recomendaciones de futuro, Madrid, Ministerio de la Presidencia, Relaciones con las Cortes y Memoria Democrática, 2020.

Etxeberria, Francisco, y Lourdes Herrasti, «Dos exhumaciones y una misma metodología en la Ribera de Navarra: de Fustiñana a Urzante», Trabajos de Arqueología Navarra, 29, 2017, pp. 15-95.

Etxeberria, Francisco et al., «Exhumación y análisis de los restos humanos recuperados en una fosa común del cementerio de Tudela (Navarra)», Munibe (AntropologiaArkeologia), 61, 2010, pp. 395-406.

Etxeberria, Francisco et al., «Exhumación, identificación y causa de muerte en la fosa común de Aibar-Oibar (Navarra)», Munibe (Antropología-Arkeologia), 63, 2012, pp. 367-377.

Etxeberria, Francisco, y Koldo Pla, El Fuerte de San Cristóbal en la memoria: de prisión a sanatorio penitenciario. El cementerio de las botellas, Pamplona, Pamiela, 2014.

Etxeberria, Francisco, Fernando Serrulla y Lourdes Herrasti, «Simas, cavernas y pozos para ocultar cadáveres en la Guerra Civil española (1936-1939. Aportaciones desde la Antropología Forense», Munibe (Antropologia-Arkeologia), 65, 2014, pp. 269-288.

Etxeberria, Francisco, y Queralt Solé, «Fosas comunes de la Guerra Civil en el siǵlo XXI: antecedentes, interdisciplinariedad y legislación», Historia Contemporánea, 60, 2019, pp. 401-438.

Federación Estatal de Foros por la Memoria, De las leyes autonómicas de memoria y la ausencia de una política de memoria estatal comprometida con las víctimas del franquismo, 2017. https://www.foroporlamemoria.info/2017/01/informe-delas-leyes-de-memoria-autonomicas/

Galella, Patricio, «La obligación de investigar las desapariciones forzadas y su aplicación a los crímenes del franquismo en España», Anuario Mexicano de Derecho Internacional, 14, 2014, pp. 77-116.

Garmendia, Gotzon, y Juan Carlos García Funes, «La Ley de Memoria Histórica de Navarra. Movimiento(s) por la recuperación de la Memoria Histórica y políticas públicas», Boletín de la Sección de Historia de la FIM, 3, 2015, pp. 70-77, http:// www.fim.org.es/02_02.php?id_publicacion=370

Garzón, Baltasar, Auto del Juzgado Central de Instrucción núm. 5 de la Audiencia Nacional, de 16 de octubre de 2008.

Gastón, José Miguel, y César Layana, Bajo tierra. Exhumaciones en Navarra 19392019, Pamplona, Gobierno de Navarra, 2019.

Gogora, Primera fase del Informe base de violaciones de derechos humanos en Euskadi durante la Guerra Civil y el Franquismo: Víctimas mortales durante la Guerra Civil y el primer franquismo (1936-1945), 2019. 
Herrasti, Lourdes, «Fosas exhumadas entre los años 2000 y 2019», en Francisco Etxeberria (coord.), Las exhumaciones de la Guerra Civil y la dictadura franquista (2000-2019). Estado actual y recomendaciones de futuro, Madrid, Ministerio de la Presidencia, Relaciones con las Cortes y Memoria Democrática, 2020, pp. $18-50$.

Herrasti, Lourdes, y Francisco Etxeberria, «Exhumaciones en Navarra. 2003-2015», en José Miguel Gastón y César Layana, Bajo tierra. Exhumaciones en Navarra 1939-2019, Pamplona, Gobierno de Navarra, 2019a, pp. 43-90.

Herrasti, Lourdes, y Etxeberria, Francisco, «Exhumaciones en Navarra. 2015-2019», en José Miguel Gastón y César Layana, Bajo tierra. Exhumaciones en Navarra 1939-2019, Pamplona, Gobierno de Navarra, 2019b, pp. 103-159.

Herrasti, Lourdes et al., «Exhumación, identificación y causa de muerte en 1936 de los restos humanos recuperados en la sima El Raso de Urbasa (Navarra)», Munibe (Antropologia-Arkeologia), 66, 2015, pp. 327-346.

Jiménez Villarejo, Antonio, y Antonio Doñate Martín, Jueces pero parciales. La pervivencia del franquismo en el poder judicial, Barcelona, Pasado y Presente, 2012.

Kerangat, Zoe de, Removiendo cielo y tierra. Las exhumaciones de víctimas del franquismo como fisuras del silencio en la transición, 2020, tesis doctoral, Universidad Autónoma de Madrid.

Majuelo, Emilio et al., Cargos públicos navarros asesinados como consecuencia de la sublevación militar de 1936, Pamplona, Universidad Pública de Navarra, memoriapaper(ak), 1, 2016, https://hdl.handle.net/2454/21122.

Majuelo, Emilio et al., «Cuantificar los hechos represivos: explicación y retos de la base de datos del fondo documental de la memoria histórica en Navarra», memoriapaper(ak), 3, 2019, https://academica-e.unavarra.es/handle/2454/33159

Martín Pallín, José Antonio, y Rafael Escudero Alday, Derecho y memoria histórica, Madrid, Trotta, 2008.

Mikelarena, Fernando, «La intensidad de la limpieza política franquista en 1936 en la Ribera de Navarra», Hispania Nova. Revista de Historia Contemporánea, 9, 2009, pp. 7-39, http://hispanianova.rediris.es/9/HN2009.pdf.

Rodríguez, Mikel, Maquis. La guerrilla vasca (1938-1962), Tafalla, Txalaparta, 2018.

Sáez, Ramón, «Los crímenes de la dictadura y la negación de acceso a la jurisdicción», en Rafael Escudero Alday y Carmen Pérez González, Desapariciones forzadas, represión política y crímenes del franquismo, Madrid, Trotta, 2013, pp. 77-100. 


\section{Relación de tablas y gráficas}

\section{Tablas}

Tabla 1: Cifras del número de víctimas de la represión franquista en Navarra aportadas los últimos años

Tabla 2: Propuesta de la tipología de las víctimas formulada por Gogora (2019)

Tabla 3: Proporción de fosas prospectadas que no se han encontrado por CCAA

Tabla 4: Porcentaje de fosas que no se han encontrado del total de las intervenidas en las distintas CCAA

Tabla 5: Síntesis de los resultados en la Comunidad Foral de Navarra actualizados a 2020

Tabla 6: Fosas en las que se han recuperado restos de los fugados de la prisión de San Cristóbal

Tabla 7: Relación cronológica de las exhumaciones realizadas en Navarra en el periodo 2005-2020

Tabla 8: Fosas exhumadas y número de individuos recuperados en Navarra

Tabla 9: Fosas exhumadas en relación al tipo de víctima

\section{Gráficas}

Gráfica 1: Evolución diacrónica de las exhumaciones en Navarra desde 2005 a 2020

Gráfica 2: Evolución de las exhumaciones en Navarra en la etapa reciente: fases

Gráfica 3: Fases con las exhumaciones más destacadas y carácter de las mismas

Gráfica 4: Fosas por tipo de víctima

Gráfica 5: Fosas exhumadas y número de individuos recuperados en función del tipo de víctima 
